\title{
The effect of HIV counselling and testing on HIV acquisition in sub-Saharan Africa: a systematic review
}

\author{
Nora E Rosenberg, ${ }^{1,2}$ Blake M Hauser, ${ }^{2,3}$ Julia Ryan, ${ }^{2,4}$ William C Miller ${ }^{1,2,5}$
}

${ }^{1}$ Department of Epidemiology, University of North Carolina, Chapel Hill, USA

${ }^{2}$ University of North Carolina Project, Lilongwe, Malawi ${ }^{3}$ Department of Environmental Science and Engineering, University of North Carolina, Chapel Hill, USA ${ }^{4}$ Department of Epidemiology and Population Health, London School of Hygiene and Tropical Medicine, London, UK ${ }^{5}$ Department of Epidemiology, Ohio State University, Columbus, USA

\section{Correspondence to} Dr Nora E Rosenberg, University of North Carolina Project, Tidziwe Center, Private Bag A-104, Lilongwe, Malawi; Nora_Rosenberg@unc.edu

Received 10 April 2016 Revised 27 June 2016 Accepted 17 July 2016 Published Online First 16 August 2016

\section{SLinked}

- http://dx.doi.org/10.1136/ sextrans-2015-052354

\section{CrossMark}

To cite: Rosenberg NE, Hauser BM, Ryan J, et al. Sex Transm Infect 2016;92:579-586.

\section{ABSTRACT}

Objectives Annually, millions of people in sub-Saharan Africa (SSA) receive HIV counselling and testing (HCT), a service designed to inform persons of their HIV status and, if HIV uninfected, reduce HIV acquisition risk. However, the impact of HCT on HIV acquisition has not been systematically evaluated. We conducted a systematic review to assess this relationship in SSA. Methods We searched for articles from SSA meeting the following criteria: an HIV-uninfected population, HCT as an exposure, longitudinal design and an HIV acquisition endpoint. Three sets of comparisons were assessed and divided into strata: sites receiving HCT versus sites not receiving $\mathrm{HCT}$ (Strata A), persons receiving HCT versus persons not receiving HCT (Strata B) and persons receiving couple HCT (CHCT) versus persons receiving individual HCT (Strata C).

Results We reviewed 1635 abstracts; eight met all inclusion criteria. Strata A consisted of one cluster randomised trial with a non-significant trend towards HCT being harmful: incidence rate ratio (IRR): 1.4. Strata $B$ consisted of five observational studies with nonsignificant unadjusted IRRs from 0.6 to 1.3. Strata C consisted of two studies. Both displayed trends towards CHCT being more protective than individual HCT (IRRs: 0.3-0.5). All studies had at least one design limitation. Conclusions In spite of intensive scale-up of HCT in SSA, few well-designed studies have assessed the prevention impacts of HCT. The limited body of evidence suggests that individual HCT does not have a consistent impact on HIV acquisition, and $\mathrm{CHCT}$ is more protective than individual HCT.

\section{INTRODUCTION}

In sub-Saharan Africa (SSA), the HIV response has intensified dramatically since 2003, when the President's Emergency Plan for AIDS Relief (PEPFAR) was introduced. HIV counselling and testing (HCT), a gateway for HIV treatment, has been brought to scale with tens of millions of annual tests. ${ }^{1-4}$ Individual and couple HCT (cHCT) are essential for linking HIV-infected persons to HIV treatment, which reduces morbidity, mortality and horizontal and vertical transmissibility. ${ }^{5}$ Similarly, individual and cHCT can now serve as referral points for HIV-uninfected men to access medical male circumcision, and, in the near future, may serve as an entry point for antiretroviral pre-exposure prophylaxis. ${ }^{7-9}$ However, historically, individual and cHCT relied strictly on behavioural HIV prevention messages. The relationship between individual and cHCT and HIV acquisition is not well understood, in spite of three decades of implementation. Given the high volume of HCT, the high proportion of negative test results and the slow scale-up of biomedical prevention, understanding the impact of individual and cHCT on HIV acquisition is essential for guiding the magnitude and nature of future HCT rollout, as well as the relative emphasis of individual and cHCT.

Individual HCT typically consists of three components: pretest counselling, HIV testing and post-test counselling. ${ }^{10}$ Typically, in pretest counselling, HIV natural history and modes of transmission are explained, as well as behavioural HIV prevention measures. In pretest counselling, the counselling is tailored to the client's personal risk factors. Currently, HIV testing is conducted with rapid tests with real-time results, but historically HIV testing was laboratory based, with results becoming available days or weeks later. Post-test counselling typically involves return of results with differentiated messages for HIV-infected and HIV-uninfected clients. For HIV-infected clients, the discussion is focused on care and treatment, psychosocial support and methods for preventing onward HIV transmission. For HIV-uninfected clients, messages address HIV acquisition through partner reduction, condom use and faithfulness to one partner.

cHCT is an approach in which two members of a couple undergo HCT together, enabling both persons to learn their own status and their partner's HIV status simultaneously. cHCT allows for a couple diagnosis: both persons HIV uninfected (HIV concordant negative), both persons HIV infected (HIV concordant positive) or one HIV infected and the other HIV uninfected (HIV discordant). Counselling messages are tailored around the couples' HIV status. In both individual and cHCT models, testing can be client or provider initiated, opt-in or opt-out and based in the clinic, home, workplace or community.

Several reviews have explored the relationship between HCT and sexual behaviour in SSA. ${ }^{11-15}$ They find that there is a strong and consistent increase in condom uptake among persons learning they are HIV infected. This effect is even stronger in cHCT, especially for HIV-discordant couples. However, the effect of HCT on sexual behaviour among HIV-uninfected persons who test alone is inconsistent.

Assessment of the impact of HCT on HIV acquisition is needed, as behaviours are imperfect proxies for HIV acquisition. Sexual behaviour is based on self-report, which can be biased from inaccurate recall and social desirability. Even 
accurate self-report may not perfectly predict HIV acquisition. Consistent condom use is associated with substantial reductions, but not elimination, of acquisition risk. ${ }^{16-20}$ Similarly, questions about condom use or number of partners may mask certain behaviours, such as serosorting or selecting partners perceived to be less risky. Thus, direct estimates of the effect of HCT on HIV acquisition are necessary.

We conducted a systematic review to assess the impact of HCT on HIV acquisition among HIV-uninfected persons in SSA. Specifically, we reviewed articles comparing (A) sites that offered full HCT with sites that did not, (B) persons who received HCT with persons who did not and (C) persons who received HCT individually with those who received HCT as a couple. We also assessed the quality of each article, including research design and analysis.

\section{METHODS}

In this review, we sought to systematically identify all published articles from SSA that assessed the impact of HCT on HIV acquisition. HCT was defined as a process that included pretest counselling, HIV testing and post-test counselling, including return of test results. Persons who tested, but did not receive their results were classified as not having received HCT. Articles were included if they met the following search criteria:

1. Conducted in SSA

2. Evaluated the impact of HCT among HIV-uninfected persons

3. Had a longitudinal study design

4. Had an HIV acquisition endpoint

5. Compared settings that provided HCT with settings that did not (Strata A), compared persons who were exposed to HCT with persons who were not (Strata B) or compared cHCT ewith individual HCT (Strata C).

Further restrictions were not made based on the nature of HCT or on methodological criteria, such as study design or analytic methods.

On 9 August 2013, PubMed and PsychINFO were searched using the following search terms: "HIV AND (acquisition OR incidence) AND testing AND counselling" to identify abstracts for review. Date of publication was not an inclusion criterion. A trained research assistant screened all abstracts and identified those that potentially met review criteria. Ambiguous abstracts, such as those that reported HIV acquisition in only one subgroup, were included at this stage. These abstracts were then screened by an epidemiologist, and when necessary the full manuscripts were reviewed. Reference lists of included manuscripts were reviewed for additional articles that potentially met inclusion criteria. These additional articles were screened using the same procedures. Duplicates were removed.

Information on the study settings, populations, study designs, intervention and comparison and HIV acquisition measures was abstracted. Setting attributes included country, year of data collection and whether HCT was workplace, community, home or clinic based. Population characteristics included age, gender and risk groups, such as general population or key populations (eg, sex workers, men who have sex with men or injection drug users).

Study designs were classified as randomised, pre/post or exposed/unexposed cohorts. Pre/post comparisons applied to persons who initially did not receive HCT and later did receive HCT. Exposed/unexposed comparisons compared persons who received HCT with those who did not receive HCT. Measures of HIV incidence were abstracted from articles as incidence rate ratios (IRRs) and/or hazard ratios (HRs) and 95\% confidence intervals (CIs). Crude, adjusted and inverse probability weighted effect measures were reported separately. When multiple subpopulations or types of analyses were included, each was reported separately. When available, subpopulation effect measures were also reported. If the original authors had not calculated these measures, but sufficient information was available, we conducted these calculations using Open Epi (http://www.OpenEpi.com).

Information on study quality and bias was abstracted as well. To assess the possibility of exposure misclassification, we assessed whether HCT status was ascertained via self-report or from clinical or study records. The number of times HCT status was ascertained was also assessed. To explore the possibility of confounding, we abstracted adjustment variables, including whether sexual risk behaviours were included. To assess the possibility of selection bias, the proportion of eligible persons who participated and the proportion of participants who were retained were abstracted. To determine the amount of information each study was contributing, the number of seroconversion events was abstracted.

Study characteristics were entered into a Microsoft Access database. Two trained research assistants reviewed each article independently. The two databases were compared for consistency by the epidemiologist, who adjudicated discrepancies. She reread all articles to validate all information in the final database.

Meta-analysis was not conducted because the studies were heterogeneous in terms of populations, study designs, effect measures and nature of HCT. Therefore, all assessments are descriptive. Our review procedures were not registered.

\section{RESULTS}

The PubMed search yielded 1622 abstracts and the PsychINFO search yielded eight abstracts. Of these abstracts, 53 were identified as potentially eligible based on the abstracts and 12 were reviewed in their entirety. One was excluded as it reported on a duplicate cohort, four were excluded for lacking a comparison population, incidence information or both and seven met all inclusion criteria. Five additional articles were identified for review from the reference lists. Of these, two were reviewed in their entirety. One was excluded for lacking a longitudinal design and one met all inclusion criteria. In total, there were eight articles included in the review (figure 1). Of these eight articles, one was in Strata A, a comparison of sites with and without $\mathrm{HCT}^{21}$ five were in Strata B, comparisons of individuals who received HCT with those who did not ${ }^{22-26}$ and two were in Strata C, comparisons of individuals who received individual HCT with those who received $\mathrm{cHCT}^{27} 28$

\section{Settings and populations}

Six articles relied on data collected before the introduction of PEPFAR in 2003, ${ }^{2122} 24-2628$ and two relied on data collected after this period ${ }^{23} 27$ (table 1). Studies were conducted in Uganda, ${ }^{22} 24 \quad 27$ Rwanda, ${ }^{28}$ Zimbabwe $^{21} 25 \quad 26$ and South Africa. ${ }^{23}$ Data were ascertained from five home-based settings, ${ }^{22-25} 27$ two workplace settings ${ }^{21} 26$ and one clinical setting. ${ }^{28}$ No studies were conducted exclusively among injecting drug users, sex workers or men who have sex with men. All were conducted among the general population with most HIV acquisition risk presumed to be through heterosexual contact. The workplace-based studies were conducted predominantly among men, ${ }^{21} 26$ the home-based studies were conducted among men and women ${ }^{22-25} 27$ and the clinical study was conducted among women attending antenatal or paediatric services. $^{28}$ One study was restricted to youth $15-24$ years old, ${ }^{23}$ and the rest were conducted in a broader range of adult ages 


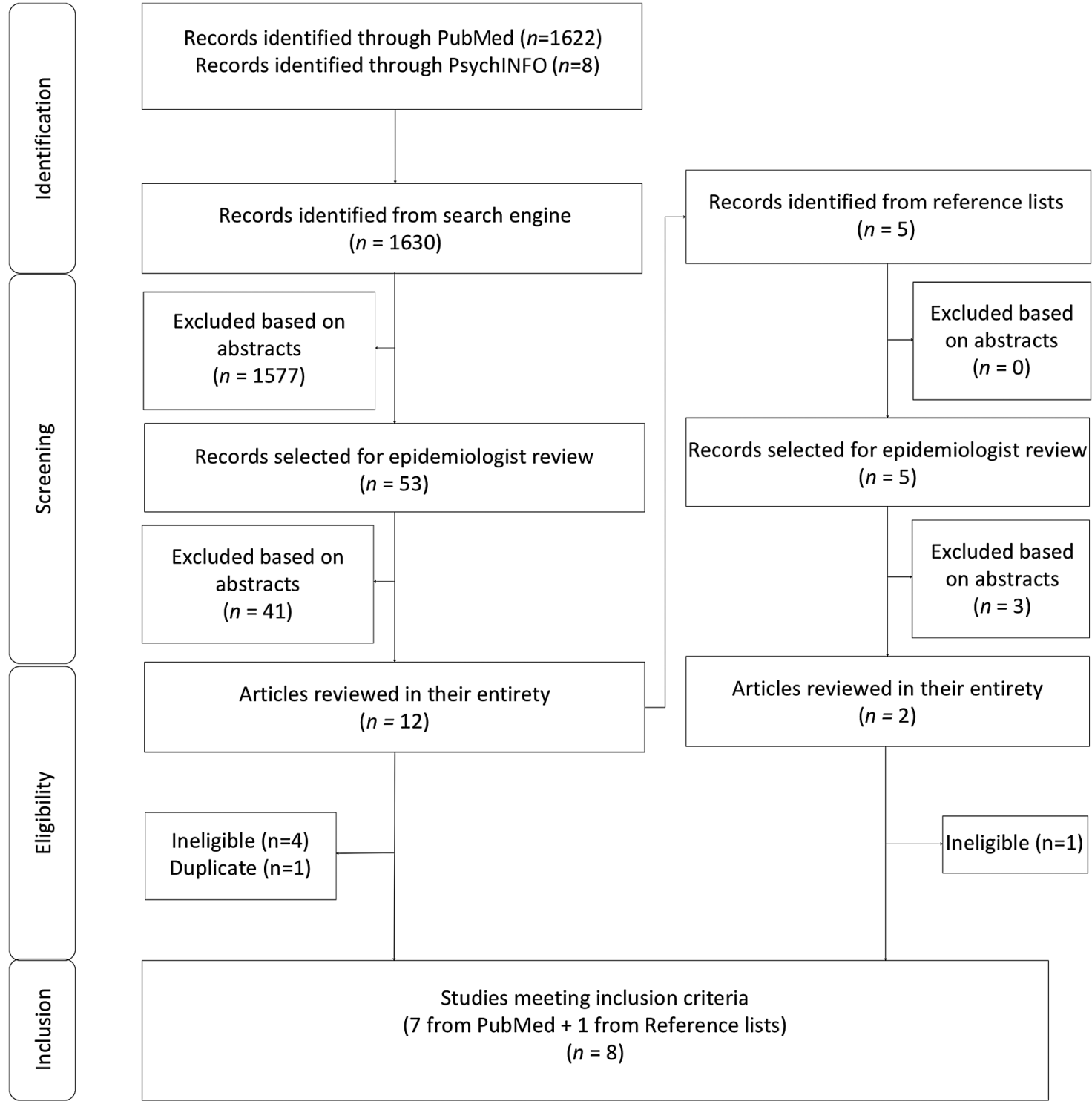

Figure 1 This consort diagram depicts the steps in the search process, including article identification, screening, eligibility, and inclusion.

Table 1 Study characteristics

\begin{tabular}{|c|c|c|c|c|c|c|}
\hline Citation & $\begin{array}{l}\text { Year } \\
\text { conducted }\end{array}$ & Country & Setting of HCT & Setting of assessment & Gender & Age range \\
\hline \multicolumn{7}{|c|}{ (A) Sites receiving $\mathrm{HCT}$ vs sites not receiving $\mathrm{HCT}$} \\
\hline Corbett et $\left.a\right|^{21}$ & 2002-2004 & Zimbabwe & Workplace (intervention) clinic (control) & Workplace & $\begin{array}{l}\text { Predominantly } \\
\text { male }\end{array}$ & $\begin{array}{l}<24 \text { to } \\
>55 \text { years }\end{array}$ \\
\hline \multicolumn{7}{|c|}{ (B) Individuals receiving $\mathrm{HCT}$ vs individuals not receiving HCT } \\
\hline Machekano et a ${ }^{26}$ & 1993-1995 & Zimbabwe & $\begin{array}{l}\text { Workplace (pretest), } \\
\text { work clinic (post-test) }\end{array}$ & Workplace & Male & $\begin{array}{l}<20 \text { to }>46 \\
\text { years }\end{array}$ \\
\hline Matovu et al ${ }^{24}$ & 1999-2000 & Uganda & Home & Population-based survey & Male and female & $15-49$ years \\
\hline Matovu et al ${ }^{22}$ & 1994-not stated & Uganda & Home & Population-based survey & Male and female & $15-49$ years \\
\hline Sherr et $a l^{25}$ & 1998-2003 & Zimbabwe & Mobile HCT & Population-based survey & Male and female & $17-54$ years \\
\hline Rosenberg et a $\left.\right|^{23}$ & 2006-2011 & $\begin{array}{l}\text { South } \\
\text { Africa }\end{array}$ & Not standardised & Population-based survey & Male and female & $15-24$ years \\
\hline \multicolumn{7}{|c|}{ (C) Individuals receiving $\mathrm{HCT}$ alone vs individuals receiving $\mathrm{HCT}$ as a couple } \\
\hline Allen et $a l^{28,32}$ & 1988-1990 & Rwanda & Clinic & Clinic & Female & $18-35$ years \\
\hline Okiria et $a l^{27}$ & 2006-2008 & Uganda & Home & $\begin{array}{l}\text { Home-based testing } \\
\text { programme }\end{array}$ & Male and female & $\begin{array}{l}13 \text { to } \\
>60 \text { years* }\end{array}$ \\
\hline
\end{tabular}

${ }^{*}$ Those 13-17 years who were married were considered emancipated minors and able to provide informed consent. Otherwise minimum age was 18 years.

HCT, HIV counselling and testing. 
with minimum ages of 13-18 years and maximum ages of 35 to $>60$ years. In all studies, HCT and cHTC were conducted by trained counsellors.

\section{Strata A}

The assessment in Strata A was a two-arm cluster randomised controlled trial conducted in Zimbabwean workplaces from 2002 to 2004. In both intervention and control sites, participants received pretest counselling at their own workplaces. In the intervention sites, persons were also able to receive HIV test results and post-test counselling at their workplaces, whereas in the control sites, persons received a voucher to off-site nearby clinics, a less convenient approach. These different approaches led to different uptake of HIV test results and post-test counselling: $5 \%$ in the control sites and $71 \%$ in interventions sites, resulting in HCT-exposed and HCT-unexposed groups in the intention-to-treat analysis. There were modest differences in the mean HIV incidence in the intervention (1.37 per 100 person years) and control sites (0.95 per 100 person years) for an intention-to-treat IRR of 1.44 (95\% CI 0.77 to 2.71 ) (table 2). In the per protocol analysis, the IRR was closer to the null: 1.34 (0.88 to 2.06). Sixty-one seroconversion events were observed (table 3). Approximately two-thirds of eligible persons participated and, of these, approximately two-thirds were retained.

\section{Strata B}

Five studies were included from Strata B. Two of these studies were conducted in Zimbabwe (1993-1995 and 1998-2003), two in Uganda (1994-non-specified and 1999-2000) and one in South Africa (2006-2011) (table 1). All were observational. Four were conducted in homes in enumerated population-based household surveys and one was conducted in a workplace setting. One study had a pre/post design, ${ }^{26}$ three had exposed/ unexposed designs 2224 and one had both. ${ }^{23}$

HIV incidence rates in the full populations ranged from $1.5^{22} 24$ to $3.5^{26}$ per 100 person years. In the full populations comparing those who received HCT with those who did not, unadjusted IRRs ranged from 0.63 to 1.28 with all CIs containing the null. ${ }^{22-26}$ In analyses disaggregated by gender, unadjusted IRRs among females ranged from 0.98 to 1.50 and unadjusted IRRs among males ranged from 0.63 to 1.40 ; none were statistically significant. Only one assessment adjusted for sexual behaviour, and in this analysis HCT was found to be protective with a HR of $0.65 .^{23}$ This study also used inverse probability weights to account for confounding and in this analysis HCT was found to be protective with a HR of 0.59. In one study in which IRRs were disaggregated based on number of partners, there was a non-significant trend towards HCT being protective among those with more than one partner (IRR: 0.50 ) but not among those with only one partner (IRR: 1.16). ${ }^{22}$

All studies had methodological limitations. None of these studies were randomised. Three did not account for confounding, ${ }^{24-26}$ one accounted for confounding in subanalyses only ${ }^{22}$ and one accounted for confounding in the main analysis. ${ }^{23}$ Participation rates were between $75 \%$ and $80 \%$ in the two studies that reported this figure. ${ }^{24}{ }^{25}$ Retention rates were 60$85 \%$ in the three studies that reported this figure. ${ }^{24-26}$ One retrospective study had sufficient information to include $54 \%$ of persons, with at least one baseline and follow-up endpoint. ${ }^{23}$ In three studies, HCT status was ascertained based on study or clinic records, 2224 and in two studies it was based on selfreport. $^{23} 25$ Studies had between 36 and 248 seroconversion events.
Strata C: CHCT versus individual HCT

Two studies were identified within Strata C. The first was conducted in Rwanda from 1988 to 1990 among women presenting for antenatal and paediatric care at an urban hospital. ${ }^{28}$ The second was conducted in Uganda from 2006 to 2008 as part of a home-based HCT programme. ${ }^{27}$ From these two studies, four IRRs were abstracted. In Rwanda, one assessment compared HIV-uninfected women before cHCT and after cHCT (pre/ post). A second compared HIV-uninfected women who received HCT alone with HIV-uninfected women who received HCT with a partner (unexposed/exposed). In both comparisons, there was a trend towards cHCT being protective: pre-post IRR: 0.44 (95\% CI 0.14 to 1.22); unexposed-exposed IRR: 0.53 (95\% CI 0.18 to 1.32 ). In Uganda, HIV acquisition was compared between HIV-uninfected persons who tested individually with those who tested with a partner. Overall, testing with a partner was significantly protective: 0.31 (95\% CI 0.19 to 0.48 ), with a stronger trend among females than males.

Combined these two studies had 135 seroconversion events. Incidence was 2.7 per 100 person years among HIV-discordant couples in Rwanda. Incidence was 0.5 per 100 person years among HIV-negative persons in unknown-status couples in Uganda. Neither study was randomised and neither adjusted for sexual behaviour. In both studies, the participation rates were not stated.

\section{DISCUSSION}

In spite of the rapid and substantial expansion of HCT in the SSA, there are few assessments of the impact of HCT on HIV acquisition, and, to our knowledge, these few assessments have not been synthesised previously. Based on this small body of evidence, two key trends emerge. First, individual HCT does not consistently increase or decrease HIV acquisition risk. Second, cHCT reduces HIV acquisition risk by approximately half compared with individual HCT. These findings must be interpreted cautiously and within a broader context, as this body of evidence is modest with imprecise estimates and possibilities of bias.

In all unadjusted analyses, when comparing those receiving HCT with those not receiving HCT, all results were close to the null and imprecise. These observations are consistent with comparable assessments in SSA and other parts of the world. Project Accept, a large cluster randomised controlled trial in SSA and Asia, comparing areas of widespread community-based HCT with more limited clinic-based HCT, found no difference in $\mathrm{HIV}$ incidence at a community level. ${ }^{29}$ In Western settings, among men who have sex with men, HCT has not been associated with decreased risk, especially among those who test repeatedly. $^{30}$

HIV-uninfected persons testing as a couple were less likely to acquire HIV than persons testing alone, a finding consistent with other evidence and models in the region. In an assessment in Uganda and Kenya, couples receiving cHCT had substantially lower HIV incidence than historical controls. ${ }^{31}$ Similarly, HIV-uninfected women in HIV-discordant couples who tested with their partners had lower HIV acquisition than HIV-uninfected women who tested alone, when assumptions were introduced about the proportion of HIV-uninfected women who were in HIV-discordant relationships. ${ }^{32}$ These findings are consistent with a mathematical model suggesting that the scale-up of cHCT could reduce HIV incidence in Zambia and Rwanda by $35-60 \% .^{33}$

Our findings are also consistent with assessments of the behavioural impacts of HCT in SSA. Individual HCT is 
Table 2 Study results

\begin{tabular}{|c|c|c|c|c|c|c|}
\hline Citation & Study design & Comparison (C) & Intervention (I) & $\begin{array}{l}\text { Seroconversions/person } \\
\text { years; incidence rate per } \\
100 \text { person years }\end{array}$ & $\begin{array}{l}\text { Unadjusted and adjusted results } \\
\text { (I vs C) }(95 \% \mathrm{Cls})\end{array}$ & Interpretation \\
\hline \multicolumn{7}{|c|}{ (A) Sites receiving $\mathrm{HCT}$ vs sites not receiving $\mathrm{HCT}$} \\
\hline $\begin{array}{l}\text { Corbett } \\
\text { et } a^{21}\end{array}$ & $\begin{array}{l}\text { Cluster } \\
\text { randomised } \\
\text { controlled trial }\end{array}$ & $\begin{array}{l}\text { Pretest counselling, risk assessment and } \\
\text { a voucher for results and post-test } \\
\text { counselling at a free-standing clinic; } \\
\text { uptake } 5.2 \%\end{array}$ & $\begin{array}{l}\text { Pretest counselling, risk assessment, } \\
\text { testing, results, post-test counselling } \\
\text { and risk reduction planning in } \\
\text { workplace; uptake } 70.7 \%\end{array}$ & $\begin{array}{l}\text { C: } 25 / 2462 ; 0.95 \text { (mean/cluster) } \\
\text { I: } 36 / 2560 ; 1.37 \text { (mean/cluster) }\end{array}$ & $\begin{array}{l}\text { IRR: } 1.44(0.79 \text { to } 2.80), p=0.4 \\
\text { alRR: } 1.49(0.77 \text { to } 2.71), p=0.5\end{array}$ & $\begin{array}{l}\text { No effect of HCT on } \\
\text { HIV acquisition }\end{array}$ \\
\hline \multicolumn{7}{|c|}{ (B) Individuals receiving HCT vs individuals not receiving HCT } \\
\hline $\begin{array}{l}\text { Machekano } \\
\text { et } \mathrm{al}^{26}\end{array}$ & Pre/post cohort & $\begin{array}{l}\text { Pretest counselling, tested for HIV but } \\
\text { did not receive HIV test results or } \\
\text { post-test counselling }\end{array}$ & $\begin{array}{l}\text { Pretest counselling, tested for HIV and } \\
\text { received results and post-test counselling }\end{array}$ & $\begin{array}{l}\text { C:16/332; } 4.82 \\
\text { I: } 20 / 657 ; 3.04\end{array}$ & IRR: 0.63 (0.31 to 1.30$), p=0.2$ & $\begin{array}{l}\text { Trend towards HCT } \\
\text { leading to lower HIV } \\
\text { acquisition }\end{array}$ \\
\hline $\begin{array}{l}\text { Matovu } \\
\text { et } a l^{24}\end{array}$ & $\begin{array}{l}\text { Exposed/ } \\
\text { unexposed cohort }\end{array}$ & $\begin{array}{l}\text { Participants who provided blood but did } \\
\text { not receive HIV test results and post-test } \\
\text { counselling at the first household survey }\end{array}$ & $\begin{array}{l}\text { Participants who provided blood and } \\
\text { received HIV test results and post-test } \\
\text { counselling at the first household survey }\end{array}$ & $\begin{array}{l}\text { C: } 35 / 2441 ; 1.4 \text { (overall) } \\
\text { I: } 42 / 2631 ; 1.6 \text { (overall) } \\
\text { C: } 11 / 1001 ; 1.1 \text { (males) } \\
\text { I: } 18 / 11661.5 \text { (males) } \\
\text { C: } 24 / 1439 ; 1.7 \text { (females) } \\
\text { I: } 24 / 1464 ; 1.6 \text { (females) }\end{array}$ & $\begin{array}{l}\text { IRR:1.11 (0.71 to } 1.75), p=0.6 \text { (overall)* } \\
\text { IRR: } 1.40 \text { ( } 0.67 \text { to } 3.08), p=0.4 \text { (males) }^{*} \\
\text { IRR: } 0.98 \text { (0.55 to } 1.74), p>0.9 \text { (females)* }^{*}\end{array}$ & $\begin{array}{l}\text { No effect of HCT on } \\
\text { HIV acquisition }\end{array}$ \\
\hline \multirow[t]{3}{*}{$\begin{array}{l}\text { Matovu } \\
\text { et } a^{22}\end{array}$} & $\begin{array}{l}\text { Exposed/ } \\
\text { unexposed cohort }\end{array}$ & $\begin{array}{l}\text { Participants who did not accept } \\
\text { home-based HCT results (entire } \\
\text { population) }\end{array}$ & $\begin{array}{l}\text { Participants who received home-based } \\
\text { HCT results once or more than once } \\
\text { (entire population) }\end{array}$ & $\begin{array}{l}\text { C: } 66 / 4038 ; 1.6 \text { (never) } \\
\text { I:76/4658; } 1.6 \text { (once); } \\
\text { I: } 48 / 3488 ; 1.4 \text { (repeat) }\end{array}$ & $\begin{array}{l}\text { IRR: } 1.00(0.72 \text { to } 1.39), p>0.9 \text { (once vs never)* } \\
\text { alRR: } 1.00(0.72 \text { to } 1.39) \text { (once vs never) } \\
\text { IRR: } 0.84(0.58 \text { to } 1.22), p=0.4 \text { (repeat vs never)* } \\
\text { alRR: } 0.85 \text { ( } 0.58 \text { to } 1.23 \text { ) (repeat vs never) }\end{array}$ & $\begin{array}{l}\text { No effect of HCT on } \\
\text { HIV acquisition }\end{array}$ \\
\hline & & $\begin{array}{l}\text { Participants who did not accept } \\
\text { home-based HCT results (those with } \\
\geq 2 \text { partners) }\end{array}$ & $\begin{array}{l}\text { Participants who received home-based } \\
\text { HCT results once or more than once } \\
\text { (those with }>2 \text { partners) }\end{array}$ & $\begin{array}{l}\text { C: } 16 / 560 ; 2.9 \text { (never) } \\
\text { I: } 9 / 631 ; 1.4 \text { (once) } \\
\text { I: } 7 / 641 ; 1.1 \text { (repeat) }\end{array}$ & $\begin{array}{l}\text { IRR: } 0.50,(0.21 \text { to } 1.12), p=0.1 \text { (once vs never) }{ }^{*} \\
\text { alRR: } 0.58(0.25 \text { to } 1.37) \text { (once vs never) } \\
\text { IRR: } 0.38,(0.15 \text { to } 0.91), p=0.03 \text { (repeat vs never) }{ }^{*} \\
\text { alRR: } 0.49(0.21 \text { to } 1.17) \text { (repeat vs never) }\end{array}$ & $\begin{array}{l}\text { Trend towards HCT } \\
\text { leading to lower HIV } \\
\text { acquisition }\end{array}$ \\
\hline & & $\begin{array}{l}\text { Participants who did not accept } \\
\text { home-based HCT results (those with } \\
\text { only one partner) }\end{array}$ & $\begin{array}{l}\text { Participants who received home-based } \\
\text { HCT results once or more than once } \\
\text { (those with only one partner) }\end{array}$ & $\begin{array}{l}\text { C: } 50 / 3478 ; 1.4 \text { (never) } \\
\text { I: } 67 / 4027 ; 1.7 \text { (once) } \\
\text { I: } 41 / 2846 ; 1.4 \text { (repeat) }\end{array}$ & $\begin{array}{l}\text { IRR: } 1.16,(0.80 \text { to } 1.67), p=0.4 \text { (once vs never) }^{*} \\
\text { alRR: } 1.15,(0.79 \text { to } 1.67) \text { (once vs never) } \\
\text { IRR: } 1.00,(0.66 \text { to } 1.51), p>0.9 \text { (repeat vs never)* } \\
\text { alRR: } 1.00 \text { ( } 0.66 \text { to } 1.51 \text { ) (repeat vs never) }\end{array}$ & $\begin{array}{l}\text { No effect of HCT on } \\
\text { HIV acquisition }\end{array}$ \\
\hline Sherr et $a l^{25}$ & $\begin{array}{l}\text { Exposed/ } \\
\text { unexposed cohort }\end{array}$ & $\begin{array}{l}\text { Persons who had never been } \\
\text { tested or counselled }\end{array}$ & $\begin{array}{l}\text { Participants who received pretest } \\
\text { counselling, testing and post-test } \\
\text { counselling }\end{array}$ & $\begin{array}{l}\text { C: } 147 / 8401 ; 1.75 \text { (overall) } \\
\text { I: } 18 / 801 ; 2.25 \text { (overall) } \\
\text { C: } 61 / 2950 ; 2.07 \text { (males) } \\
\text { I: } 10 / 462 ; 2.16 \text { (males) } \\
\text { C: } 86 / 5451 ; 1.58 \text { (females) } \\
\text { I: } 8 / 339 ; 2.36 \text { (females) }\end{array}$ & $\begin{array}{l}\text { IRR: } 1.28 \text { ( } 0.77 \text { to } 2.05), p=0.3 \text { (overall)* }^{*} \\
\text { alRR: } 1.30 \text { (0.79 to } 2.14) \text { (overall) } \\
\text { IRR: } 1.05(0.51 \text { to } 1.98), p=0.9 \text { (males) } \\
\text { alRR: } 1.08 \text { ( } 0.62 \text { to } 1.82) \text { (males) } \\
\text { IRR: } 1.50 \text { (0.68 to } 2.95), p=0.3 \text { (females)* } \\
\text { alRR: } 1.55 \text { (0.63 to } 3.84 \text { ) (females) }\end{array}$ & $\begin{array}{l}\text { No effect of HCT on } \\
\text { HIV acquisition }\end{array}$ \\
\hline $\begin{array}{l}\text { Rosenberg } \\
\text { et } a l^{23}\end{array}$ & $\begin{array}{l}\text { Exposed/ } \\
\text { unexposed and } \\
\text { pre/post cohort }\end{array}$ & $\begin{array}{l}\text { Participants who had not been tested } \\
\text { for HIV and learnt their results }\end{array}$ & $\begin{array}{l}\text { Participants who had been tested for } \\
\text { HIV and learnt their results }\end{array}$ & $\begin{array}{l}\text { C: } 131 / 4702 ; 2.79 \\
\text { I: } 117 / 3834 ; 3.05\end{array}$ & $\begin{array}{l}\text { HR: } 1.02(95 \% \mathrm{Cl} 0.79 \text { to } 1.31), \mathrm{p}=0.5 \\
\text { aHR: } 0.65(95 \% \mathrm{Cl} 0.50 \text { to } 0.86), \mathrm{p}<0.01 \\
\text { ipwHR: } 0.59(95 \% \mathrm{Cl} 0.45 \text { to } 0.78), p<0.01\end{array}$ & $\begin{array}{l}\text { HCT leads to lower } \\
\text { HIV acquisition, but } \\
\text { only after } \\
\text { adjustment }\end{array}$ \\
\hline
\end{tabular}




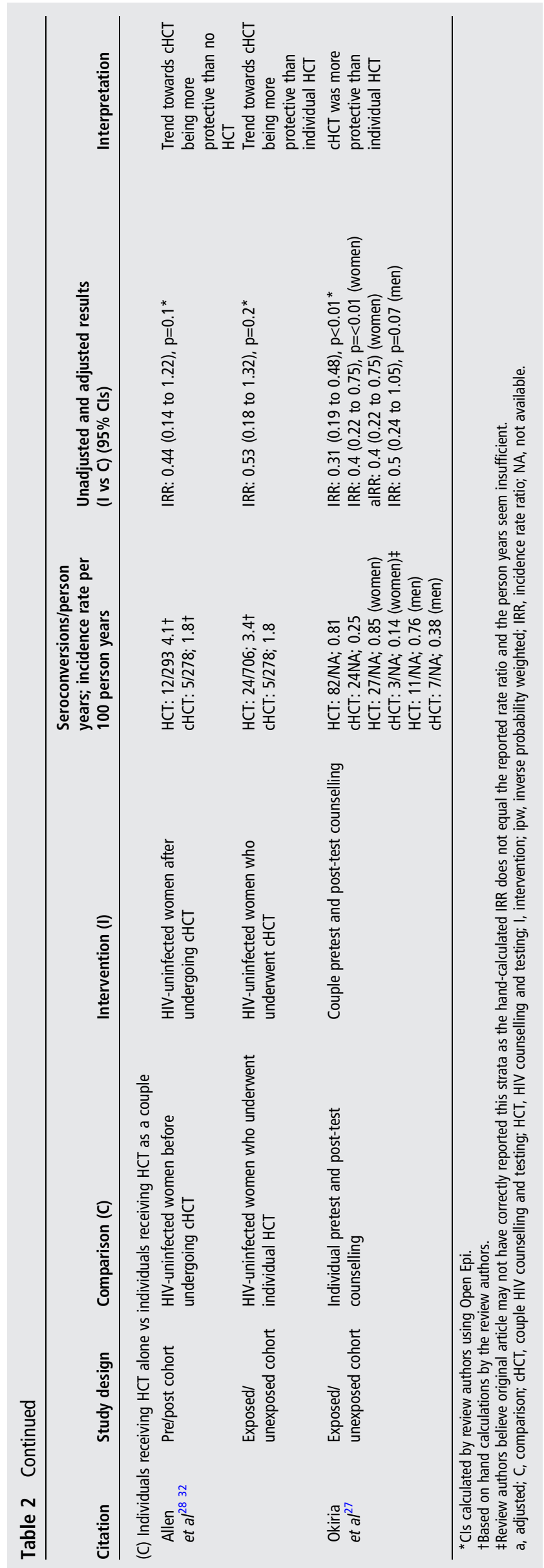

associated with modest behaviour change in some HIV-uninfected populations, but not others. ${ }^{11}$ However, cHCT is consistently and strongly associated with uptake of consistent condom use, especially in HIV-discordant couples, with meta-analysed ORs in excess of $60 .{ }^{12-143435}$ The greater effectiveness of cHCT is likely due to the importance of dyadic interventions for sexual activities which are dyadic behaviours. ${ }^{36-38}$ Regardless of why, promoting cHCT over individual HCT is a key policy implication. Although the WHO has endorsed cHCT for the region, it remains the exception, not the norm. Several strategies, such as partner notification and community invitations have been effective for increasing $\mathrm{CHCT}$ and could have important implications if brought to scale. ${ }^{39-41}$ Such efforts would have benefits on reduced HIV incidence and on reaching global HIV targets, including the 90-90-90 goals and elimination of mother-to-child transmission ${ }^{42-44}$

Assessing the impact of HCT on HIV acquisition is methodologically challenging. First, all assessments of HIV acquisition require large cohorts followed for long periods with low, nondifferential loss to follow-up. These longitudinal studies are time consuming and expensive. Second, the impact of HCT on HIV acquisition cannot be assessed in randomised settings; deliberate withholding of HCT is unethical due to the incontrovertible benefits for HIV-infected persons. As a result, observational designs are typically employed, but these are less rigorous, especially without controlling for confounders. A third challenge is that both the primary exposure (HCT) and the primary outcome (HIV acquisition) require an HIV test. Thus, it is necessary to have independent ascertainment methods for establishing HCT (the exposure) and acquisition (the outcome). In some studies, the exposure is based on self-report, making it subject to information bias. In some assessments, persons refuse to provide blood for outcome ascertainment, introducing potential bias.

In light of these methodological challenges, this body of literature is small and methodologically weak. Only eight articles are included with fewer than 1000 seroconversion events, providing a limited foundation for drawing conclusions. Furthermore, all studies have important limitations. The study in Strata A was randomised at the cluster level. However, participation and retention were moderate, with possibilities for selection bias. All assessments in Strata B and Strata C were non-randomised, and most did not control for key confounders: sexual behaviour and pregnancy. In the study that did control for these factors, HCT had no effect on HIV acquisition in unadjusted analysis but was protective in adjusted analysis. ${ }^{23}$ This difference suggests that those who received HCT were at higher risk for HIV than those who did not; HCT helped lower the risk of testers (a higher risk population) to a level similar to that of non-testers (a lower risk population). It is not clear whether similar effects would have been observed, had other strata B studies controlled for these variables.

Integrating new biomedical advances into HCT is an important direction for future HCT programming. Most of these studies were conducted in the 1990 s and early 2000 s, prior to the findings that medical male circumcision and pre-exposure prophylaxis can be effective at reducing HIV acquisition rates among HIV-uninfected persons. ${ }^{7-9}$ 45-48 As such, HCT in these studies was focused on behavioural prevention messages. To enhance its effectiveness, HCT can be used as a platform for providing referrals for biomedical prevention.

HCT with simple behavioural messages, when offered to HIV-uninfected persons without their sexual partners, is insufficient to consistently and substantially prevent HIV acquisition. 
Table 3 Study quality

\begin{tabular}{|c|c|c|c|c|c|c|c|c|}
\hline Citation & Randomised & $\begin{array}{l}\text { Number of } \\
\text { seroconversions }\end{array}$ & $\begin{array}{l}\text { HCT (exposure) } \\
\text { ascertainment }\end{array}$ & $\begin{array}{l}\text { HIV (outcome) } \\
\text { ascertainment }\end{array}$ & $\begin{array}{l}\text { Number of } \\
\text { times HCT } \\
\text { ascertained }\end{array}$ & $\begin{array}{l}\text { Participation } \\
\text { rate }\end{array}$ & $\begin{array}{l}\text { Retention } \\
\text { rate }\end{array}$ & $\begin{array}{l}\text { Adjustment } \\
\text { methods }\end{array}$ \\
\hline \multicolumn{9}{|c|}{ (A) Sites receiving $\mathrm{HCT}$ vs sites not receiving $\mathrm{HCT}$} \\
\hline Corbett et al, $2007^{21}$ & Yes & 61 & Study records & Study records & Once & $72 \%$ & $69 \%$ & $\begin{array}{l}\text { Baseline HIV } \\
\text { prevalence and age }\end{array}$ \\
\hline \multicolumn{9}{|c|}{ (B) Individuals receiving $\mathrm{HCT}$ vs individuals not receiving $\mathrm{HCT}$} \\
\hline Machekano et $a l^{26}$ & No & 36 & Study records & Study records & $\begin{array}{l}\text { More than } \\
\text { once }\end{array}$ & Not stated & $85 \%$ & None \\
\hline Matovu et $a l^{24}$ & No & 77 & $\begin{array}{l}\text { Household } \\
\text { survey records }\end{array}$ & $\begin{array}{l}\text { Household } \\
\text { survey records }\end{array}$ & Once & $78 \%$ & $67 \%$ & None \\
\hline Matovu et $a^{22}$ & No & 190 & $\begin{array}{l}\text { Household } \\
\text { survey records }\end{array}$ & $\begin{array}{l}\text { Household } \\
\text { survey records }\end{array}$ & $\begin{array}{l}\text { More than } \\
\text { once }\end{array}$ & Not stated & Not stated & $\begin{array}{l}\text { Age, gender, } \\
\text { marital status, } \\
\text { education, current } \\
\text { non-regular } \\
\text { relationship, } \\
\text { condom use in the } \\
\text { past } 6 \text { months }\end{array}$ \\
\hline Sherr et al ${ }^{25}$ & No & 165 & Self-report & $\begin{array}{l}\text { Household } \\
\text { survey records }\end{array}$ & Once & $79 \%$ & $61 \%$ & Age and sex \\
\hline Rosenberg et $a l^{23}$ & No & 248 & Self-report & $\begin{array}{l}\text { Household } \\
\text { survey records }\end{array}$ & $\begin{array}{l}\text { More than } \\
\text { once }\end{array}$ & $\begin{array}{l}54 \% \text { of person } \\
\text { sufficient inforn } \\
\text { inclusion in an }\end{array}$ & $\begin{array}{l}\text { had } \\
\text { ation for } \\
\text { ysis }\end{array}$ & $\begin{array}{l}\text { Age, gender, } \\
\text { distance to the } \\
\text { nearest clinic, } \\
\text { education, sexual } \\
\text { debut, condom } \\
\text { use, number of sex } \\
\text { partners, } \\
\text { pregnancy, } \\
\text { fatherhood }\end{array}$ \\
\hline \multicolumn{9}{|c|}{ (C) Individuals receiving HCT alone vs individuals receiving $\mathrm{HCT}$ as a couple } \\
\hline Allen et $a l^{2832}$ & No & 29 & Study records & Study records & $\begin{array}{l}\text { More than } \\
\text { once }\end{array}$ & Not stated & $\begin{array}{l}92 \% \text { at } \\
2 \text { years }\end{array}$ & None \\
\hline Okiria et $a^{27}$ & No & 106 & $\begin{array}{l}\text { Programmatic } \\
\text { records }\end{array}$ & $\begin{array}{l}\text { Programmatic } \\
\text { records }\end{array}$ & Once & Not stated & Not stated & HIV symptoms, age \\
\hline
\end{tabular}

HCT, HIV counselling and testing.

However, HCT, when offered to HIV-infected persons, is critical for treatment initiation and subsequent reductions in transmissibility. Considering the effects of HCT on both HIV-uninfected and HIV-infected persons, HCT scale-up must continue. However, to maximise the prevention impacts, a paradigm shift towards cHCT is needed, along with improved linkages to biomedical prevention for those who are HIV uninfected and at high risk of HIV acquisition.

\section{Key messages}

- In spite of intensive scale-up of HIV counselling and testing (HCT) in sub-Saharan Africa, a few well-designed studies have assessed the prevention impacts of HCT.

- Individual HCT is neither consistently protective nor harmful.

- Couple HCT ( $\mathrm{CHCT}$ ) is more protective than individual HCT.

- Interventions beyond HCT are needed for substantial declines in HIV acquisition, including $\mathrm{CHCT}$.

Contributors NER conceptualised the study in collaboration with WCM. BH conducted the search and reviewed all abstracts. BH and JR reviewed and coded all full articles; NER adjudicated discrepancies. NER and BH wrote the first draft. All authors provided substantive edits to the manuscript and approved the final draft.

Funding National Institute of Mental Health (K99MH104154-01A1), National Institute of Allergy and Infectious Diseases (P30 Al50410), Fogarty International Center (R25 TW009340).
Competing interests None declared.

Provenance and peer review Commissioned; externally peer reviewed.

\section{REFERENCES}

1 Parekh BS, Kalou MB, Alemnji G, et al. Scaling up HIV rapid testing in developing countries: comprehensive approach for implementing quality assurance. Am J Clin Pathol 2010;134:573-84.

2 WHO, UNAIDS, UNICEF. HIV Testing and Counseling. Towards Universal Access: Scaling up Priority HIVIAIDS Interventions in the Health Sector. Progress Report 2010. 2010.

3 UNAIDS. Global Report: UNAIDS Report on the Global AIDS Epidemic, 2010.

4 Mitchell S, Cockcroft A, Lamothe G, et al. Equity in HIV testing: evidence from a cross-sectional study in ten Southern African countries. BMC Int Health Hum Rights 2010;10:23.

5 Cohen MS, Chen YQ, McCauley M, et al. Prevention of HIV-1 infection with early antiretroviral therapy. N Engl J Med 2011;365:493-505.

6 Bor J, Herbst AJ, Newell ML, et al. Increases in adult life expectancy in rural South Africa: valuing the scale-up of HIV treatment. Science 2013;339:961-5.

7 Auvert B, Taljaard D, Lagarde E, et al. Randomized, controlled intervention trial of male circumcision for reduction of HIV infection risk: the ANRS 1265 Trial. PLoS Med 2005;2:e298

8 Gray RH, Kigozi G, Serwadda D, et al. Male circumcision for HIV prevention in men in Rakai, Uganda: a randomised trial. Lancet 2007;369:657-66.

9 Bailey RC, Moses S, Parker CB, et al. Male circumcision for HIV prevention in young men in Kisumu, Kenya: a randomised controlled trial. Lancet 2007;369:643-56.

10 Department of Health Republic of South Africa. National HIV counselling and testing policy guidelines, 2015.

11 Weinhardt LS, Carey MP, Johnson BT, et al. Effects of HIV counseling and testing on sexual risk behavior: a meta-analytic review of published research, 1985-1997. Am J Public Health 1999;89:1397-405.

12 Burton J, Darbes LA, Operario D. Couples-focused behavioral interventions for prevention of HIV: systematic review of the state of evidence. AIDS Behav 2010;14:1-10. 
13 Kennedy CE, Medley AM, Sweat MD, et al. Behavioural interventions for HIV positive prevention in developing countries: a systematic review and meta-analysis. Bull World Health Organ 2010;88:615-23.

14 LaCroix JM, Pellowski JA, Lennon CA, et al. Behavioural interventions to reduce sexual risk for HIV in heterosexual couples: a meta-analysis. Sex Transm Infect 2013;89:620-7.

15 Denison JA, O'Reilly KR, Schmid GP, et al. HIV voluntary counseling and testing and behavioral risk reduction in developing countries: a meta-analysis, 1990-2005. AIDS Behav 2008;12:363-73.

16 Hughes JP, Baeten JM, Lingappa JR, et al. Determinants of per-coital-act HIV-1 infectivity among African HIV-1-serodiscordant couples. J Infect Dis 2012;205:358-65.

17 Weller SC. A meta-analysis of condom effectiveness in reducing sexually transmitted HIV. Soc Sci Med 1993;36:1635-44.

18 Pinkerton SD, Abramson PR. Effectiveness of condoms in preventing HIV transmission. Soc Sci Med 1997;44:1303-12.

19 Davis KR, Weller SC. The effectiveness of condoms in reducing heterosexual transmission of HIV. Fam Plann Perspect 1999;31:272-9.

20 Pinkerton SD, Abramson PR, Turk ME. Updated estimates of condom effectiveness. J Assoc Nurses AIDS Care 1998;9:88-21.

21 Corbett EL, Makamure B, Cheung YB, et al. HIV incidence during a cluster-randomized trial of two strategies providing voluntary counselling and testing at the workplace, Zimbabwe. AIDS 2007;21:483-9.

22 Matovu JK, Gray RH, Kiwanuka N, et al. Repeat voluntary HIV counseling and testing (VCT), sexual risk behavior and HIV incidence in Rakai, Uganda. AIDS Behav 2007:11:71-8

23 Rosenberg NE, Westreich D, Bärnighausen T, et al. Assessing the effect of HIV counselling and testing on HIV acquisition among South African youth. AIDS 2013;27:2765-73.

24 Matovu JK, Gray RH, Makumbi F, et al. Voluntary HIV counseling and testing acceptance, sexual risk behavior and HIV incidence in Rakai, Uganda. AIDS 2005;19:503-11.

25 Sherr L, Lopman B, Kakowa M, et al. Voluntary counselling and testing: uptake, impact on sexual behaviour, and HIV incidence in a rural Zimbabwean cohort. AIDS 2007;21:851-60.

26 Machekano R, McFarland W, Mbizvo MT, et al. Impact of HIV counselling and testing on HIV seroconversion and reported STD incidence among male factory workers in Harare, Zimbabwe. Cent Afr J Med 1998;44:98-102.

27 Okiria AG, Okui O, Dutki M, et al. HIV incidence and factors associated with seroconversion in a rural community home based counseling and testing program in Eastern Uganda. AIDS Behav 2014;18(Suppl 1):S60-8.

28 Allen S, Serufilira A, Bogaerts J, et al. Confidential HIV testing and condom promotion in Africa. Impact on HIV and gonorrhea rates. JAMA 1992:268:3338-43.

29 Coates TJ, Kulich M, Celentano DD, et al. Effect of community-based voluntary counselling and testing on HIV incidence and social and behavioural outcomes (NIMH Project Accept; HPTN 043): a cluster-randomised trial. Lancet Glob Health 2014;2:e267-77.

30 MacKellar DA, Valleroy LA, Secura GM, et al. Repeat HIV testing, risk behaviors, and HIV seroconversion among young men who have sex with men: a call to monitor and improve the practice of prevention. J Acquir Immune Defic Syndr 2002;29:76-85.

31 Celum C, Baeten JM. Serodiscordancy and HIV prevention in sub-Saharan Africa. Lancet 2013:381:1519-21.

32 Allen $\mathrm{S}$, Tice J, Van de Perre $\mathrm{P}$, et al. Effect of serotesting with counselling on condom use and seroconversion among HIV discordant couples in Africa. BMJ 1992;304:1605-9.

33 Dunkle KL, Stephenson R, Karita E, et al. New heterosexually transmitted HIV infections in married or cohabiting couples in urban Zambia and Rwanda: an analysis of survey and clinical data. Lancet 2008;371:2183-91.

34 Rosenberg NE, Pettifor AE, Bruyn GD, et al. HIV testing and counseling leads to immediate consistent condom use Among South African stable HIV-discordant couples. J Acquir Immune Defic Syndr 2013;62:226-33.

35 Bunnell R, Opio A, Musinguzi J, et al. HIV transmission risk behavior among HIV-infected adults in Uganda: results of a nationally representative survey. AIDS 2008;22:617-24.

36 Lewis MA, McBride CM, Pollak Kl, et al. Understanding health behavior change among couples: an interdependence and communal coping approach. Soc Sci Med 2006;62:1369-80.

37 Montgomery CM, Watts C, Pool R. HIV and dyadic intervention: an interdependence and communal coping analysis. PLOS ONE 2012;7:e40661.

38 Ware NC, Wyatt MA, Haberer JE, et al. What's love got to do with it? Explaining adherence to oral antiretroviral pre-exposure prophylaxis for HIV-serodiscordant couples. J Acquir Immune Defic Syndr 2012;59:463-8.

39 Rosenberg NE, Mtande TK, Saidi F, et al. Recruiting male partners for couple HIV testing and counselling in Malawi's option B+ programme: an unblinded randomised controlled trial. Lancet HIV 2015;2:e483-91.

40 Wall K, Karita E, Nizam A, et al. Influence network effectiveness in promoting couples' HIV voluntary counseling and testing in Kigali, Rwanda. AIDS 2012;26:217-27.

41 Wall KM, Kilembe W, Nizam A, et al. Promotion of couples' voluntary HIV counselling and testing in Lusaka, Zambia by influence network leaders and agents. BMJ Open 2012;2

42 Were WA, Mermin JH, Wamai N, et al. Undiagnosed HIV infection and couple HIV discordance among household members of HIV-infected people receiving antiretroviral therapy in Uganda. J Acquir Immune Defic Syndr 2006;43:91-5.

43 Stirratt MJ, Remien RH, Smith A, et al. The role of HIV serostatus disclosure in antiretroviral medication adherence. AIDS Behav 2006;10:483-93.

44 Aluisio AR, Bosire R, Betz B, et al. Male partner participation in antenatal clinic services is associated with improved HIV-free survival among infants in Nairobi, Kenya: a prospective cohort study. J Acquir Immune Defic Syndr 2016.

45 Baeten J, Celum C. Oral antiretroviral chemoprophylaxis: current status. Curr Opin HIV AIDS 2012;7:514-19.

46 Baeten JM, Donnell D, Ndase P, et al. Antiretroviral prophylaxis for HIV prevention in heterosexual men and women. N Engl J Med 2012;367:399-410.

47 Van Damme L, Corneli A, Ahmed K, et al. Preexposure prophylaxis for HIV infection among African women. N Engl J Med 2012;367:411-22.

48 Abdool Karim SS, Richardson BA, Ramjee G, et al. Safety and effectiveness of BufferGel and $0.5 \%$ PRO2000 gel for the prevention of HIV infection in women. AIDS 2011;25:957-6. 